\title{
Robust Bimetallic Ultramicroporous Metal-Organic Framework for Separation and Purification of Noble gases
}

Ting Wang, ${ }^{\dagger}$ Yun-Lei Peng, ${ }^{\dagger}$ En Lin,,${ }^{\dagger}$ Zheng Niu, ${ }^{\perp}$ Pengfei Li,,$"$ Shengqian Ma,${ }^{\perp}$ Peng Zhao, ${ }^{*}{ }^{\dagger}$ Yao Chen, ${ }^{\ddagger}$ Peng Cheng ${ }^{\dagger, \S}$ and Zhenjie Zhang ${ }^{*}, \dagger,+, s$,

${ }^{\dagger}$ College of Chemistry, Nankai University, Tianjin, 300071, People’s Republic of China

${ }^{\sharp}$ State Key Laboratory of Medicinal Chemical biology, Nankai University, Tianjin 300071, People's Republic of China

${ }^{\S}$ Key Laboratory of Advanced Energy Materials Chemistry (MOE), Nankai University, Tianjin 300071, People's Republic of China

"Department of Chemistry, Hebei Normal University of Science \& Technology, Qinhuangdao 066004, Hebei Province, People's Republic of China

${ }^{\perp}$ Department of Chemistry, University of South Florida, 4202 E. Fowler Avenue, Tampa, Florida 33620, United States

\section{Materials and Methods}

\section{General materials}

2,3-dichloropyrazine (98\%, Bide Pharmatech Ltd), sodium hydrosulfide (NaHS, LiDeShi), sodium hydroxide (NaOH, AR, Tianjinhuaxueliuchang), copper(II) perchlorate hexahydrate $\left(\mathrm{Cu}\left(\mathrm{ClO}_{4}\right)_{2} \cdot 6 \mathrm{H}_{2} \mathrm{O}, 98 \%\right.$, Alfa $)$, nickel(II) perchlorate hexahydrate $\left(\mathrm{Ni}\left(\mathrm{ClO}_{4}\right)_{2} \bullet 6 \mathrm{H}_{2} \mathrm{O}\right.$, reagent-grade, alfa), copper(I) iodide (CuI, $>99.5 \%$, aladdin), iodide ( $\mathrm{I}_{2}, \mathrm{AR}$, TIANJINGFENGCHUAN), acetonitrile, ether and acetone were purchased and used without further purification. The PXRD patterns were obtained by Ultima IV. The adsorption of Ar was collected by Micromeritics ASAP 2460 and $\mathrm{N}_{2}, \mathrm{Kr}$ and Xe were collected by Micromeritics ASAP 2020.

Powder X-ray diffraction (PXRD) analysis. 
Powder x-ray diffraction data was collected using microcrystalline samples on a Rigaku Ultima IV diffractometer $(40 \mathrm{kV}, 40 \mathrm{~mA}, \mathrm{CuK} \alpha 1,2 \lambda=1.5418 \AA$ ). The measured parameter included a scan speed of $1\left(^{\circ}\right) / \mathrm{min}$, a step size of $0.02\left(^{\circ}\right)$ and a scan range from $5\left(^{\circ}\right)$ to $50\left(^{\circ}\right)$.

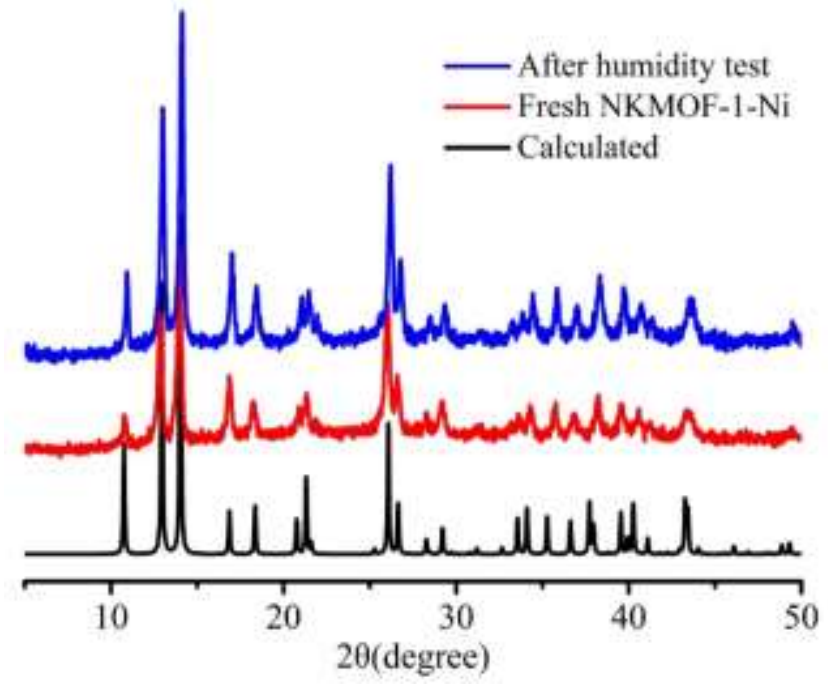

Figure S1. The PXRD pattern of calculated (black). Fresh NKMOF-1-Ni (red). NKMOF-1-Ni after measuring 70\% humidity stability (blue).

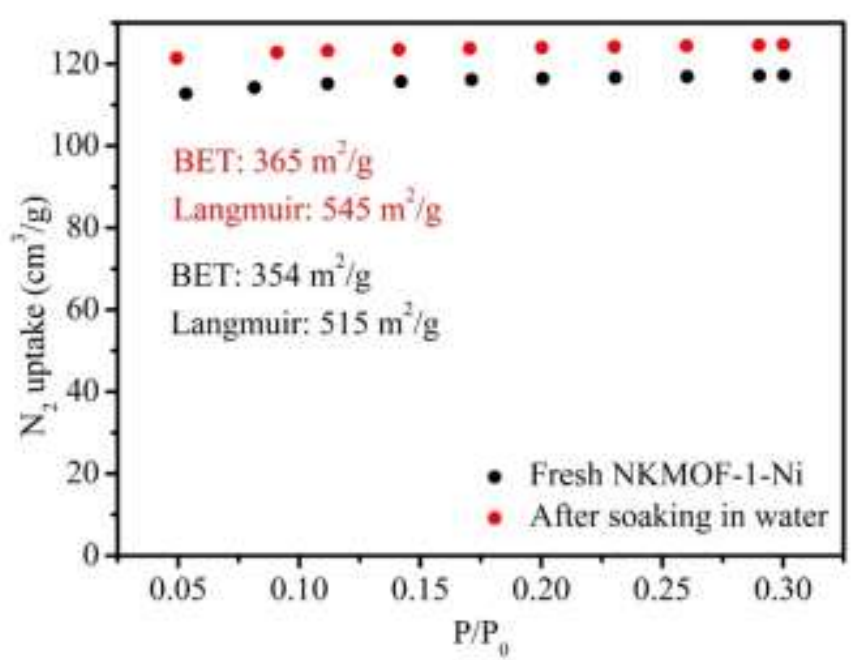

Figure S2. BET and Langmuir surface area of fresh NKMOF-1-Ni (black) and NKMOF-1-Ni after soaking in water for 1.5 years (red). 


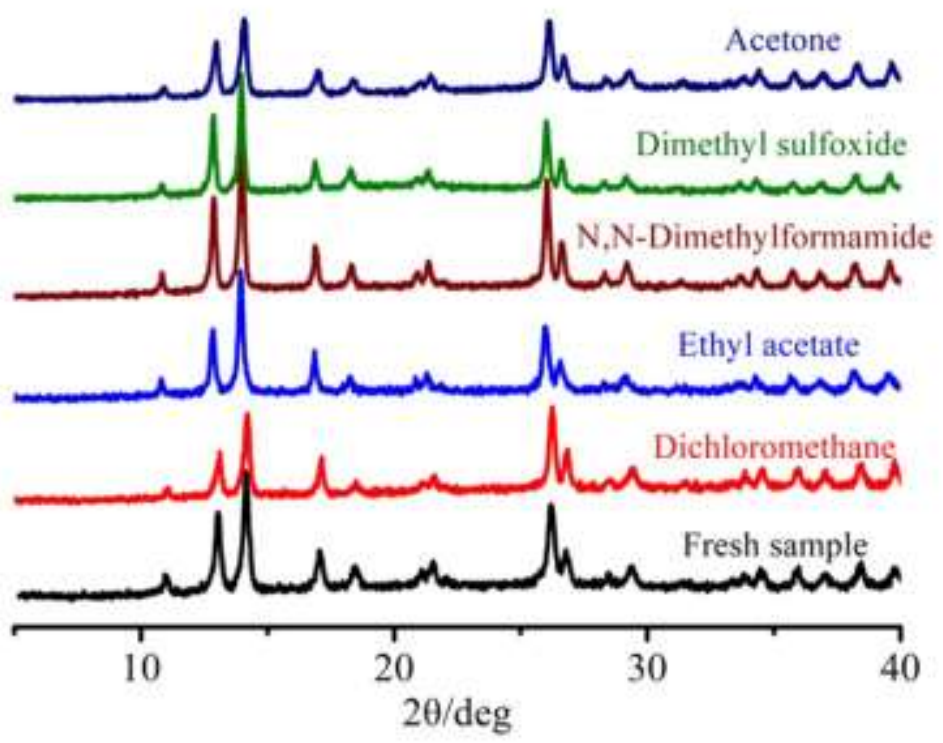

Figure S3. The PXRD patterns of solvents stability of NKMOF-1-Ni.

\section{Single component gas adsorption}

We used the powder sample of NKMOF-1-Ni to test single component gas adsorption. NKMOF-1-Ni were evacuated at $363 \mathrm{~K}$ for $10 \mathrm{~h}$ under dynamic pressure below $5 \mu \mathrm{m}$ Hg. Single-component gas adsorption isotherms were measured at 273 K, 298 K. The purity of single component gas is $99.999 \%$. 

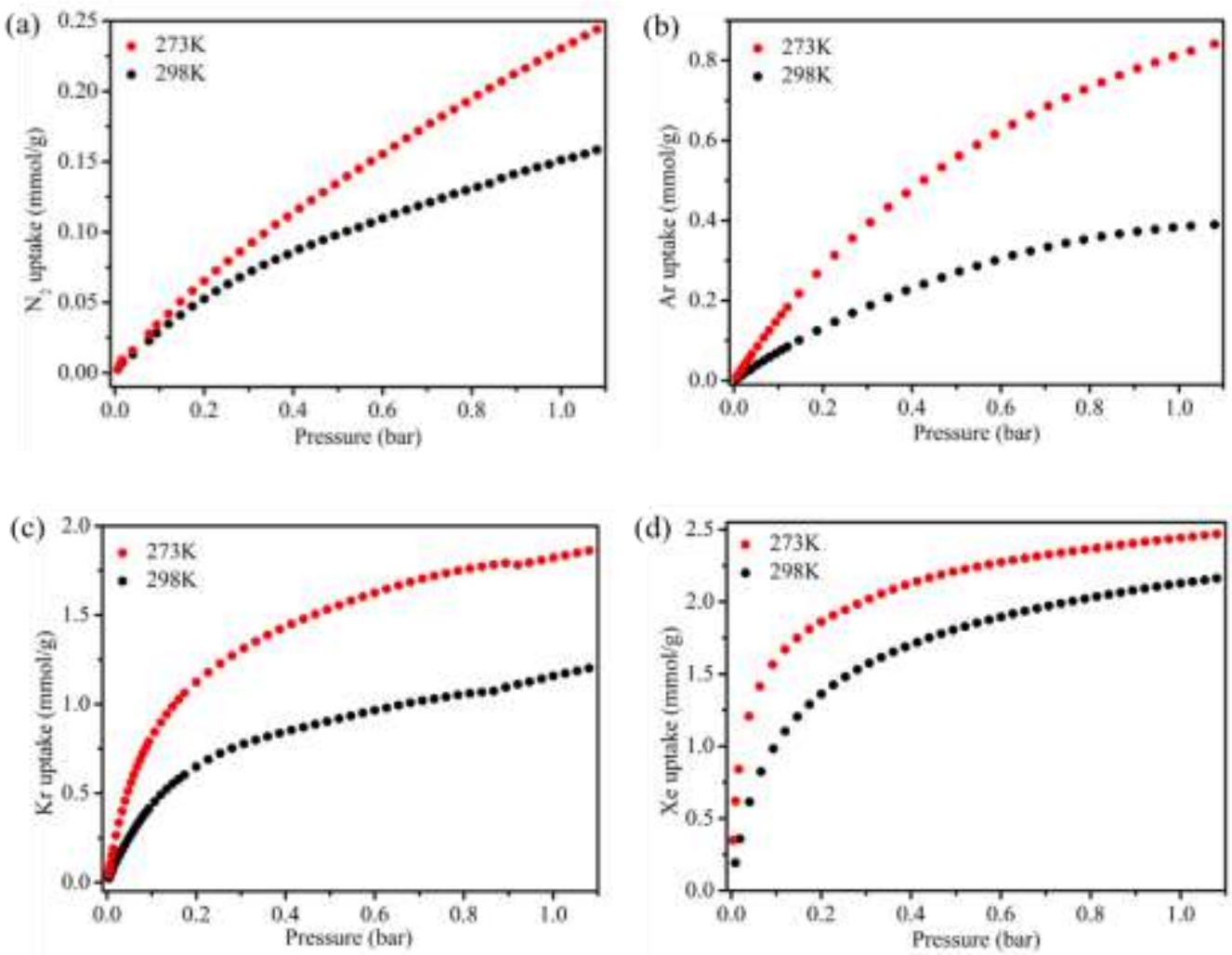

Figure S4. The isotherm curves of single component gas for NKMOF-1-Ni. The red curve represents $273 \mathrm{~K}$ and the black curve represents $298 \mathrm{~K}$, respectively. (a) $\mathrm{N}_{2}$, (b) Ar, (c) Kr, and (d) Xe.

\section{Isosteric heats of adsorption $\left(Q_{\text {st }}\right)$ of noble gases for NKMOF-1-Ni}

The $\mathrm{Q}_{\text {st }}$ of noble gases was calculated by Virial method. The single component adsorption was fitted by Virial equation (1):

$$
\ln \mathrm{P}=\ln \mathrm{N}+\frac{1}{T} \sum_{i=0}^{m} a_{i} N^{i}+\sum_{i=0}^{n} b_{i} N^{i}
$$

Where $\mathrm{N}(\mathrm{mmol} / \mathrm{g})$ is the amount of gas adsorbed at the pressure $\mathrm{P}(\mathrm{mmHg}), \mathrm{a}_{\mathrm{i}}$ and $\mathrm{b}_{\mathrm{i}}$ are virial coefficients, $\mathrm{T}$ is the temperature in $\mathrm{K}, \mathrm{m}$ and $\mathrm{n}$ are the number of coefficients require to adequately describe the isotherm. To calculate $\mathrm{Q}_{\mathrm{st}}$, the fitting parameters from the above equation were used for the following equation (2):

$$
\mathrm{Qst}=-\mathrm{R} \sum_{i=0}^{\mathrm{m}} a_{i} N^{i}
$$

Where $\mathrm{R}$ is the universal gas constant. 
(a)

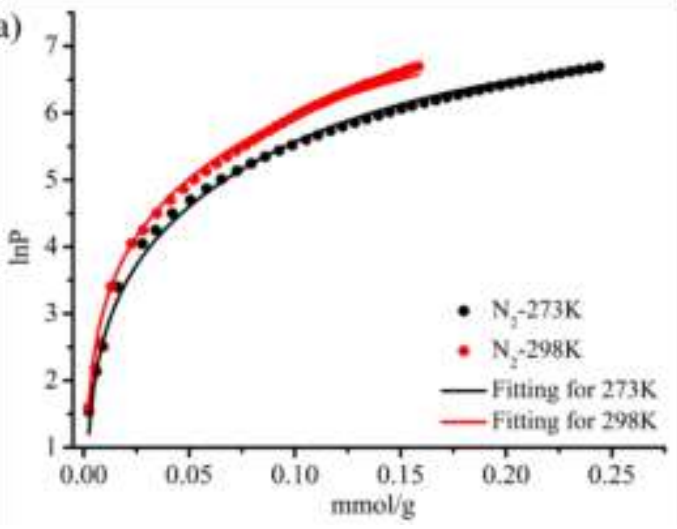

\begin{tabular}{|c|c|c|}
\hline \multirow[t]{2}{*}{ Equation } & \multicolumn{2}{|c|}{ 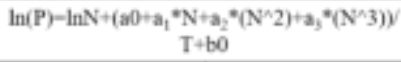 } \\
\hline & Value & Standard error \\
\hline$a_{0}$ & -1449.89236 & 70.64821 \\
\hline$a_{1}$ & 2638.50905 & 377,30488 \\
\hline a. & -8505.75611 & 3710.27308 \\
\hline $\mathbf{a}_{3}$ & 6931.2906 & 10135.93872 \\
\hline$b_{0}$ & 12.50243 & 0.24744 \\
\hline $\mathbf{R}^{2}$ & \multicolumn{2}{|c|}{0.99456} \\
\hline
\end{tabular}

(b)

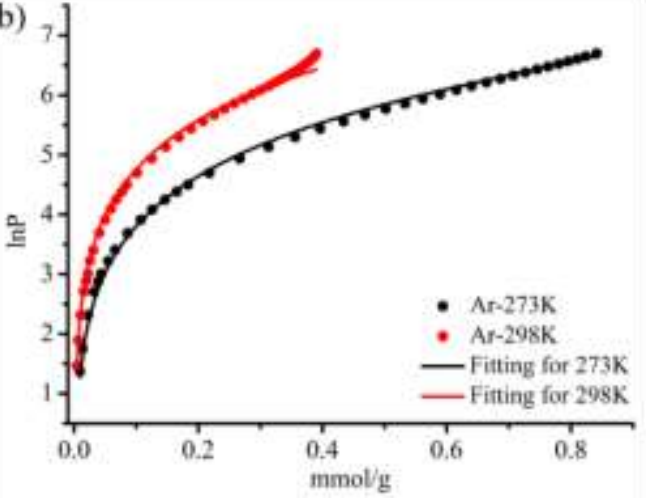

\begin{tabular}{|c|c|c|}
\hline Equation & $\ln (\mathrm{P})-\ln \mathrm{N}+\left(\mathrm{a}_{0}+\mathrm{a}_{1}{ }^{*} \mathrm{~N}+\mathrm{a}_{2}{ }^{*}\left(\mathrm{~N}^{N} 2\right)+\mathrm{a}_{3}{ }^{*}\left(\mathrm{~N}^{*} 3\right)\right) \mathrm{T}+\mathrm{b}_{9}$ \\
\hline & Value & Standard error \\
\hline $\mathrm{a}_{9}$ & -3140.79956 & 75.97154 \\
\hline $\mathrm{a}_{8}$ & 555.48525 & 99.39663 \\
\hline $\mathrm{a}_{2}$ & -646.99115 & 317.74657 \\
\hline $\mathrm{a}_{3}$ & 394.8565 & 263.41105 \\
\hline $\mathrm{b}_{8}$ & 17.43556 & 0.26618 \\
\hline $\mathrm{R}^{2}$ & \multicolumn{2}{|c|}{0.99657} \\
\hline
\end{tabular}

(c)

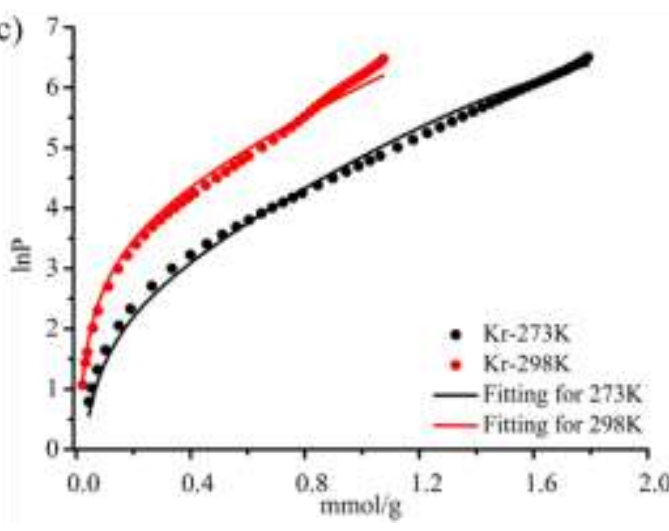

\begin{tabular}{|c|c|c|}
\hline Equation & $\ln (\mathrm{P})=\ln \mathrm{N}+\left(\mathrm{a}_{0}+\mathrm{a}_{1}{ }^{*} \mathrm{~N}+\mathrm{a}_{2}{ }^{*}(\mathrm{~N} / 2)+\mathrm{a}_{3}{ }^{*}(\mathrm{~N} / 3)\right) / \mathrm{T}+\mathrm{b}_{6}$ \\
\hline & Value & Standard error \\
\hline $\mathrm{a}_{0}$ & -4144.90114 & 101.87019 \\
\hline $\mathrm{a}_{1}$ & 120.16868 & 71.16312 \\
\hline $\mathrm{a}_{2}$ & 313.43809 & 95.3173 \\
\hline $\mathrm{a}_{3}$ & -111.7816 & 34.81068 \\
\hline $\mathrm{b}_{6}$ & 18.85876 & 0.35426 \\
\hline $\mathrm{R}^{2}$ & \multicolumn{2}{|c|}{0.99227} \\
\hline
\end{tabular}

(d)

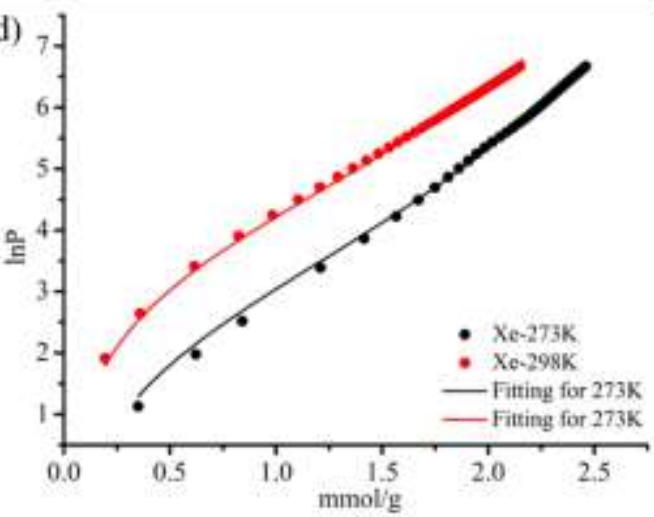

\begin{tabular}{|c|c|c|}
\hline Equation & $\ln (\mathbf{P})-\ln N+\left(a_{0}+a_{1}{ }^{*} N^{*}+a_{2}{ }^{*}\left(N^{\wedge} 2\right)+a_{3}{ }^{*}\left(N^{\wedge} 3\right) y T+b_{0}\right.$ \\
\hline & Value & Standard error \\
\hline$a_{0}$ & -4116.26001 & 52.30961 \\
\hline$a_{1}$ & 290.30098 & 50.3734 \\
\hline$a_{2}$ & -38.19718 & 38.47923 \\
\hline$a_{3}$ & 37.1286 & 8.81539 \\
\hline$b_{0}$ & 17.05783 & 0.16387 \\
\hline$R^{2}$ & \multicolumn{2}{|c|}{0.99788} \\
\hline
\end{tabular}

Figure S5. The fitted isotherms of single component adsorption isotherms at $273 \mathrm{~K}$ and 298 K by Virial equation. (a) Fitted for $\mathrm{N}_{2}$. (b) Fitted for Ar. (c) Fitted for Kr. (d) Fitted for Xe. 


\section{Ideal adsorbed solution theory (IAST) selectivity $^{1}$}

Dual-site Langmuir-Freundlich Model for $\mathrm{Xe}, \mathrm{Kr}, \mathrm{Ar}$ and $\mathrm{N}_{2}$ adsorption isotherms:

The dual-site Langmuir-Freundlich Model expressed as follows (3):

$$
q=q_{m 1} \frac{k_{1} p^{t_{1}}}{1+k_{1} p^{t_{1}}}+q_{m 2} \frac{k_{2} p^{t_{2}}}{1+k_{2} p^{t_{2}}}
$$

Here, $\mathrm{p}$ is the pressure of the bulk gas at equilibrium with the adsorbed phase $(\mathrm{kPa})$, $\mathrm{q}$ is the adsorbed amount per mass of adsorbent ( $\mathrm{mol} / \mathrm{kg}), \mathrm{q}_{\mathrm{m} 1}$ and $\mathrm{q}_{\mathrm{m} 2}$ are the saturation capacities of sites 1 and $2(\mathrm{~mol} / \mathrm{kg}), \mathrm{k}_{1}, \mathrm{k}_{2}$ is the affinity coefficient.

Final selectivity for adsorbate $\mathrm{i}$ relative to adsorbate $\mathrm{j}$ was calculated using follow equation (4):

$$
S_{i / j}=\frac{x_{i} / x_{j}}{y_{i} / y_{j}}
$$

Here, $x_{i}$ and $x_{j}$ are the mole fractions of components $i$ and $j$ in the adsorbed phase, respectively, and $y_{i}$ and $y_{j}$ are the mole fractions of components $i$ and $j$ in the gas phase. Respectively.

Table S1. The fitted parameters of Ar, Kr, Xe and $\mathrm{N}_{2}$ by dual-site Langmuir-Freundlich Model

\begin{tabular}{|c|c|c|c|c|}
\hline & $\mathrm{Ar}$ & $\mathrm{Kr}$ & $\mathrm{Xe}$ & $\mathrm{N}_{2}$ \\
\hline$q_{m 1}$ & 0.17654 & 1.25661 & 1.42305 & 0.51382 \\
\hline$q_{m 2}$ & 0.30312 & 1.20653 & 1.63347 & 0.19589 \\
\hline$k_{1}$ & $4.12119 \mathrm{E}-5$ & 0.05218 & 0.14418 & $1.33857 \mathrm{E}-6$ \\
\hline$k_{2}$ & 0.0244 & $1.80657 \mathrm{E}-10$ & 0.02284 & 0.01802 \\
\hline$t_{1}$ & 2.52098 & 1.00094 & 0.95332 & 2.28476 \\
\hline$t_{2}$ & 1.09511 & 4.34971 & 0.82109 & 1.00259 \\
\hline$R^{2}$ & 0.99994 & 0.99999 & 0.99999 & 0.99984 \\
\hline
\end{tabular}

\section{Modeling Studies}

Lattice Parameters. The parametrizations in this work was based on the crystal structure for NKMOF-1-Cu collected in our former work. In order to obtain the crystal 
structure of NKMOF-1-Ni, Ni was used to substitute all copper atoms in $\mathrm{CuS}_{4}$ unit of NKMOF-1-Cu, and then the structure was completely relaxed by using the $\mathrm{DMOL}_{3}$ program package in the Materials Studio of Accelrys Inc. We used the Perdew - Bruke Ernzerhof $(\mathrm{PBE})^{2}$ functional under the generalized gradient approximation (GGA) functional for our calculations. Grimme method was used for the DFT-D correction. And double numerical plus polarization (DNP) basis set was utilized for all atoms. The optimized lattice parameters obtained for NKMOF-1-Ni were listed in Table S2.

Table S2. The optimized lattice parameters for NKMOF-1-Ni.

\begin{tabular}{|c|c|}
\hline Lattice Parameter & NKMOF-1-Ni \\
\hline $\mathrm{a}(\AA)$ & 6.98620 \\
\hline $\mathrm{b}(\AA)$ & 6.98620 \\
\hline $\mathrm{c}(\AA)$ & 16.3040 \\
\hline$\alpha\left(^{\circ}\right)$ & 90 \\
\hline$\beta\left(^{\circ}\right)$ & 90 \\
\hline$\gamma\left({ }^{\circ}\right)$ & 90 \\
\hline
\end{tabular}

Grand Canonical Monte Carlo (GCMC) Calculations. In this work, the GCMC calculations were performed in a $3 \times 3 \times 2$ supercell of NKMOF-1-Ni with periodic boundary conditions to understand the interaction between noble gases and the frameworks. All the simulations were performed using the Sorption module of Material Studio software. For each thermodynamic state, the equilibration steps and the production steps were all set to $1.0 \times 10^{7}$. The framework atoms were held fixed during the simulations. A Lennard-Jones (LJ) cut-off distance of $10.2333 \AA$ was used for the simulations to represent the Van der Waals interaction, this value corresponded to half the shortest system cell dimension length. Coulomb interactions were turned off since noble gases are neutral. The LJ parameters for all atoms were obtained from the Dreiding force field, and if not available in Dreiding force field, ${ }^{3}$ from the Universal Force Field (UFF). ${ }^{4}$ Tables of LJ potential parameters for NKMOF-1-Ni were listed in Table S3. 
Table S3. Lennard-Jones parameters for the atoms in the framework of NKMOF-1-Ni.

\begin{tabular}{|c|c|c|c|c|c|c|}
\hline Atoms & $\mathrm{C}$ & $\mathrm{H}$ & $\mathrm{N}$ & $\mathrm{S}$ & $\mathrm{Cu}$ & $\mathrm{Ni}$ \\
\hline$\sigma(\AA)$ & 3.89 & 3.19 & 3.66 & 4.03 & 3.49 & 2.83 \\
\hline$\varepsilon / k_{\mathrm{B}}(\mathrm{K})$ & 47.55 & 7.6 & 38.7 & 172 & 2.5 & 7.5 \\
\hline
\end{tabular}

\section{Simulate breakthrough curves $\mathrm{Xe} / \mathrm{Kr} / \mathrm{Ar} / \mathbf{N}_{2}$ of NKMOF-1-Ni}

We used a software named 3P simulation to simulate the breakthrough curves of $\mathrm{Xe} / \mathrm{Kr}$ (20/80), Xe/Ar (1/99), Xe/N 2 (1/99), Xe/Kr/Ar (20/20/20):

First, fitted the single-component adsorption isotherms by DS langmuirSIPS, the equation was displayed as following equation (5):

$$
q=\frac{q_{m}}{2}\left(\frac{k_{1} p}{1+k_{1} p}+\frac{\left(k_{2} p\right)^{t}}{1+\left(k_{2} p\right)^{t}}\right)
$$

Here, $\mathrm{q}$ is the amount adsorbed per mass of material (in $\mathrm{mmol} / \mathrm{g}$ ), $\mathrm{p}$ is the total pressure (in bar) of the bulk gas at equilibrium with the adsorbed phase, $\mathrm{q}_{\mathrm{m}}$ is the max loading of each gas (in mmol/g), $\mathrm{k}_{1}$ (in bar $^{-1}$ ) is the affinity constant of site 1 , and the $\mathrm{k}_{2}\left(\right.$ in bar $\left.^{-1}\right)$ is the affinity constant of site $2, \mathrm{t}$ is Sipsexponent.

Table S4. The fitted parameters of $\mathrm{Xe}, \mathrm{Kr}, \mathrm{Ar}$ and $\mathrm{N}_{2}$ by DS langmuirSIPS

\begin{tabular}{|c|c|c|c|c|}
\hline & $\mathrm{Xe}$ & $\mathrm{Kr}$ & $\mathrm{Ar}$ & $\mathrm{N}_{2}$ \\
\hline Affinity constant $1 \mathrm{k}_{1}(1 / \mathrm{bar})$ & 15.625244 & 5.22028 & 3.53272 & 1.70492 \\
\hline Affinity constant $2 \mathrm{k}_{2}(1 / \mathrm{bar})$ & 1.394366 & 0.569675 & 1.86787 & 0.44258 \\
\hline Max. loading $(\mathrm{mmol} / \mathrm{g})$ & 2.793654 & 2.515809 & 0.49283 & 0.41321 \\
\hline Sipsexponent t & 1.00636 & 4.360676 & 2.0445 & 2.69643 \\
\hline
\end{tabular}

We chose the IAST with DSLAISIPS model to simulate the breakthrough curves, the parameters were listed below:

\section{Binary mixtures:}

Table S5. The parameters of binary mixture of $\mathrm{Xe} / \mathrm{Kr}$

\begin{tabular}{ccc}
\hline Property & Unit & Value \\
\hline S8
\end{tabular}




\begin{tabular}{|c|c|c|}
\hline Adsorber height & $\mathrm{cm}$ & 15 \\
\hline Adsorber diameter & $\mathrm{cm}$ & 0.6 \\
\hline Environmental temperature & $\mathrm{K}$ & 298 \\
\hline Gas flow & $\mathrm{cm}^{3} / \mathrm{min}$ & 5 \\
\hline Pressure & bar & 1 \\
\hline Adsorbent mass & $\mathrm{g}$ & 1.5 \\
\hline Bed porosity & - & 0.34 \\
\hline Molecular weight of carrier gas & $\mathrm{g} / \mathrm{mol}$ & 4 \\
\hline Number of components & - & 2 \\
\hline Affinity constant 1 for Xe & $1 /$ bar & 15.625244 \\
\hline Affinity constant 1 for $\mathrm{Kr}$ & $1 /$ bar & 5.22028 \\
\hline Affinity constant 2 for Xe & $1 /$ bar & 1.394366 \\
\hline Affinity constant 2 for $\mathrm{Kr}$ & $1 /$ bar & 0.569675 \\
\hline Max. Loading for Xe & $\mathrm{mmol} / \mathrm{g}$ & 2.793654 \\
\hline Max. Loading for $\mathrm{Kr}$ & $\mathrm{mmol} / \mathrm{g}$ & 2.515809 \\
\hline Sipsexponent for Xe & - & 1.00636 \\
\hline Sipsexponent for $\mathrm{Kr}$ & - & 4.360676 \\
\hline Concentration for Xe & Vol.\% & 16 \\
\hline Concentration for $\mathrm{Kr}$ & Vol.\% & 64 \\
\hline Molar weight for $\mathrm{Xe}$ & $\mathrm{g} / \mathrm{mol}$ & 131.293 \\
\hline Molar weight fo $\mathrm{r} \mathrm{Kr}$ & $\mathrm{g} / \mathrm{mol}$ & 83.79 \\
\hline
\end{tabular}

Table S6. The parameters of binary mixture of Xe/Ar

\begin{tabular}{lll}
\hline Property & Unit & Value \\
\hline Adsorber height & $\mathrm{cm}$ & 15 \\
\hline Adsorber diameter & $\mathrm{cm}$ & 0.6 \\
\hline Environmental temperature & $\mathrm{K}$ & 298 \\
\hline Gas flow & $\mathrm{cm}^{3} / \mathrm{min}$ & 5 \\
\hline
\end{tabular}




\begin{tabular}{|c|c|c|}
\hline Pressure & bar & 1 \\
\hline Adsorbent mass & $\mathrm{g}$ & 1.5 \\
\hline Bed porosity & - & 0.34 \\
\hline Molecular weight of carrier gas & $\mathrm{g} / \mathrm{mol}$ & 4 \\
\hline Number of components & - & 2 \\
\hline Affinity constant 1 for Xe & $1 /$ bar & 15.625244 \\
\hline Affinity constant 1 for Ar & $1 /$ bar & 3.53272 \\
\hline Affinity constant 2 for Xe & $1 /$ bar & 1.394366 \\
\hline Affinity constant 2 for $\mathrm{Ar}$ & $1 /$ bar & 1.86787 \\
\hline Max. Loading for Xe & $\mathrm{mmol} / \mathrm{g}$ & 2.793654 \\
\hline Max. Loading for Ar & $\mathrm{mmol} / \mathrm{g}$ & 2.515809 \\
\hline Sipsexponent for Xe & - & 1.00636 \\
\hline Sipsexponent for Ar & - & 2.0445 \\
\hline Concentration for $\mathrm{Xe}$ & Vol.\% & 0.8 \\
\hline Concentration for Ar & Vol.\% & 79.2 \\
\hline Molar weight for $\mathrm{Xe}$ & $\mathrm{g} / \mathrm{mol}$ & 131.293 \\
\hline Molar weight for Ar & $\mathrm{g} / \mathrm{mol}$ & 39.948 \\
\hline
\end{tabular}

Table S7. The parameters of binary mixture of $\mathrm{Xe} / \mathrm{N}_{2}$

\begin{tabular}{lll}
\hline Property & Unit & Value \\
\hline Adsorber height & $\mathrm{cm}$ & 15 \\
\hline Adsorber diameter & $\mathrm{cm}$ & 0.6 \\
\hline Environmental temperature & $\mathrm{K}$ & 298 \\
\hline Gas flow & $\mathrm{cm}^{3} / \mathrm{min}$ & 5 \\
\hline Pressure & $\mathrm{bar}$ & 1 \\
\hline Adsorbent mass & $\mathrm{g}$ & 1.5 \\
\hline Bed porosity & - & 0.34 \\
\hline Molecular weight of carrier gas & $\mathrm{g} / \mathrm{mol}$ & 4 \\
\hline
\end{tabular}




\begin{tabular}{lll}
\hline Number of components & - & 2 \\
\hline Affinity constant 1 for Xe & $1 / \mathrm{bar}$ & 15.625244 \\
\hline Affinity constant 1 for $\mathrm{N}_{2}$ & $1 / \mathrm{bar}$ & 1.70492 \\
\hline Affinity constant 2 for $\mathrm{Xe}$ & $1 / \mathrm{bar}$ & 1.394366 \\
\hline Affinity constant 2 for $\mathrm{N}_{2}$ & $1 / \mathrm{bar}$ & 0.44258 \\
\hline Max. Loading for $\mathrm{Xe}$ & $\mathrm{mmol} / \mathrm{g}$ & 2.793654 \\
\hline Max. Loading for $\mathrm{N}_{2}$ & $\mathrm{mmol} / \mathrm{g}$ & 0.41321 \\
\hline Sipsexponent for $\mathrm{Xe}$ & - & 1.00636 \\
\hline Sipsexponent for $\mathrm{N}_{2}$ & - & 2.69643 \\
\hline Concentration for $\mathrm{Xe}_{\text {Concentration for } \mathrm{N}_{2}}$ & $\mathrm{Vol} \% \mathrm{~g}$ & 0.8 \\
\hline Molar weight for $\mathrm{Xe}$ & $\mathrm{Vol} \% \mathrm{~g} / \mathrm{mol}$ & 79.2 \\
\hline Molar weight for $\mathrm{N}_{2}$ & $\mathrm{~g} / \mathrm{mol}$ & 131.293 \\
\hline
\end{tabular}

Table S8. The parameters of ternary mixture of $\mathrm{Xe} / \mathrm{Kr} / \mathrm{Ar}$

\begin{tabular}{lll}
\hline Property & Unit & Value \\
\hline Adsorber height & $\mathrm{cm}$ & 15 \\
\hline Adsorber diameter & $\mathrm{cm}$ & 0.6 \\
\hline Environmental temperature & $\mathrm{K}$ & 298 \\
\hline Gas flow & $\mathrm{cm}^{3} / \mathrm{min}$ & 5 \\
\hline Pressure & $\mathrm{bar}$ & 1 \\
\hline Adsorbent mass & $\mathrm{g}$ & 1.5 \\
\hline Bed porosity & - & 0.34 \\
\hline Molecular weight of carrier gas & $\mathrm{g} / \mathrm{mol}$ & 4 \\
\hline Number of components & - & 2 \\
\hline Affinity constant 1 for Xe & $1 / \mathrm{bar}$ & 15.625244 \\
\hline Affinity constant 1 for $\mathrm{Kr}$ & $1 / \mathrm{bar}$ & 5.22028 \\
\hline Affinity constant 1 for Ar & $1 / \mathrm{bar}$ & 3.53272 \\
\hline
\end{tabular}




\begin{tabular}{lll}
\hline Affinity constant 2 for Xe & $1 / \mathrm{bar}$ & 1.394366 \\
\hline Affinity constant 2 for $\mathrm{Kr}$ & $1 / \mathrm{bar}$ & 0.569675 \\
\hline Affinity constant 2 for $\mathrm{Ar}$ & $1 / \mathrm{bar}$ & 1.86787 \\
\hline Max. Loading for $\mathrm{Xe}$ & $\mathrm{mmol} / \mathrm{g}$ & 2.793654 \\
\hline Max. Loading for $\mathrm{Kr}$ & $\mathrm{mmol} / \mathrm{g}$ & 2.515809 \\
\hline Max. Loading for $\mathrm{Ar}$ & $\mathrm{mmol} / \mathrm{g}$ & 0.49283 \\
\hline Sipsexponent for $\mathrm{Xe}$ & - & 1.00636 \\
\hline Sipsexponent for $\mathrm{Kr}$ & - & 4.360676 \\
\hline Sipsexponent for $\mathrm{Ar}$ & - & 2.0445 \\
\hline Concentration for $\mathrm{Xe}$ & $\mathrm{Vol} \%$ & 20 \\
\hline Concentration for $\mathrm{Kr}$ & $\mathrm{Vol} \% \%$ & 20 \\
\hline Concentration for $\mathrm{Ar}$ & $\mathrm{Vol} \%$ & 20 \\
\hline Molar weight for $\mathrm{Xe}$ & $\mathrm{g} / \mathrm{mol}$ & 131.293 \\
\hline Molar weight for $\mathrm{Kr}$ & $\mathrm{g} / \mathrm{mol}$ & 83.79 \\
\hline Molar weight for $\mathrm{Ar}$ & $\mathrm{g} / \mathrm{mol}$ & 39.948 \\
\hline
\end{tabular}

\section{Reference:}

(3) Myers, A. L.; Prausnitz, J. M. Thermodynamics of mixed-gas adsorption. AIChE J. 1965, 11, $121-127$

(4) Perdew, J. P.; Burke, K.; Ernzerhof, M. Generalized Gradient Approximation Made Simple. Phys. Rev. Lett. 1996, 77, 3865-3868.

(5) Mayo, S. L.; Olafson, B. D.; Goddard, W. A. DREIDING: a generic force field for molecular simulations. J. Phys. Chem. 1990, 94, 8897-8909.

(6) Rappe, A. K.; Casewit, C. J.; Colwell, K. S.; Goddard, W. A.; Skiff, W. M. UFF, a full periodic table force field for molecular mechanics and molecular dynamics simulations. J. Am. Chem. Soc. 1992, $114,10024-10035$. 